\title{
New method of nutrient management in hydroponics and the application for production of low potassium tomato fruit
}

\author{
Satoru Tsukagoshi*, Miho Aoki \\ University of Chiba, Japan
}

\begin{abstract}
Chronic kidney failure has become a global problem in recent years, and the patients are often restricted $K$ intake because of the problem with excretion of excess $K$. Low $K$ tomato fruit will improve the dietary habits of the patients and their QOL. In this study, a method of producing tomato fruit with low $K$ content was investigated. Medium-sized and cherry tomato (Solanum Lycopersicum $L$.) cultivars were used, and the supply of $\mathrm{K}$ was restricted using hydroponic technology. In medium-sized tomatoes, fruit $K$ content decreased $40 \%$ to $60 \%$ depending on cultivar by $\mathrm{K}$ withdrawal from the nutrient solution. Although total soluble solid content showed a slight decrease, titratable acid content was affected by $K$ restriction and decreased $20 \%$ to $40 \%$ depending on cultivar. In either case, $K$ withdrawn in hydroponic culture from anthesis of the 3rd truss was effective in producing tomato fruit with low $K$, and could decrease the fruit $K$ content to at least $50 \%$ of the expected tomato fruit $K$ content. Next study, we applied the newly developed management method, quantitative management, about nutrient supply in hydroponics to control the $K$ supply more precisely. In quantitative management, total amount of nutrients necessary for the plants to achieve their life cycle is divided by the estimated cultivation period. And the calculated amount of fertilizers is supplied to the solution tank at every regular interval. Low $\mathrm{K}$ fruit $(100 \mathrm{mg} \mathrm{K} / 100 \mathrm{~g}$ fruit) was achieved when $0.9 \mathrm{~g}$ of potassium was supplied. From these results, restriction of $K$ supply in hydroponics with double or triple truss system is hopeful to produce low $\mathrm{K}$ tomato fruits, and quantitative control is thought to be more suitable for low $K$ tomato production. Further study is necessary to expect the cultivation period accurately before the cultivation to plan the schedule of K supply.
\end{abstract}

Keywords: Hydroponics, Tomato cultivation, Nutrition

\section{Introduction}

Hydroponics is a sub branch of hydro culture which is a method of growing plants without the use of soil by using media of mineral nutrient solutions in a water solvent. Terrestrial plants can be grown with only their roots exposed or subjected to the nutritious liquid or the roots may be physically supported by an inert medium like perlite, gravel or other sterile substrates. Despite inert media, roots can cause changes in the rhizosphere $\mathrm{pH} \&$ root exudates can impact the biology of rhizosphere [1,2].

The nutrient substances used in hydroponic systems can be made from many different sources, including materials like fish excrement, duck manure, purchased chemical fertilizers or artificial nutrient solutions $[3,4]$.

Plants generally grown hydroponically on inert media include tomatoes, cucumbers, peppers, lettuces, marijuana and model plants like Arabidopsis thaliana [5].

Hydroponics offers many advantages, one of them leads to a decrease in water usage for agriculture purposes. To grow $1 \mathrm{~kg}$ of tomatoes using methods intensive farming requires $400 \mathrm{~L}$ of water using hydroponics, $70 \mathrm{~L}$ and only $20 \mathrm{~L}$ using aeroponics. Since it takes much less water to grow produce [6].
It can provide optimal levels of micronutrients and macronutrients at certain amounts that are required for plants for their growth and development of plants in nutrient media.

There are two main variations for each medium, sub-irrigation and top irrigation. For all techniques, most hydroponic reservoirs are now built of plastic but other materials have been used including concrete, glass, metal, vegetable solids \& wood. The containers should exclude light to prevent algae and fungal growth in the nutrient solution: Static solution culture, Continuous-flow solution culture, Aeroponics, Fogponics, Passive sub-irrigation, Ebb and flow (flood and drain) sub-irrigation, Runto-waste, Deep water culture, Top-fed deep water culture [7].

\section{Conclusion}

Hydroponics research concludes that it can provide all the nutrients that are required for the plant and growth and development in optimal conditions. The nutrient composing added for the media will shows its effect on plant growth. Growing of plants in nutrient media will also provide the disease free plants as soil borne diseases will be reduces as soil usage is zero and one

Volume 4, Issue 4 
can provide optimal levels of nutrients required for plants for their growth and development.

\section{Biography}

Satoru Tsukagoshi has his expertise in Hydroponic Vegetable Production, especially management method of nutrient solution and improvement of products' quality. In recent years, his research activity spreads through the field of Plant Factory. He takes some classes about Hydroponic Technologies for foreign students and overseas engineers in Chiba University. Chiba University has concluded the agreements on the joint project about plant factory using artificial light and advanced environment control with some foreign research institutes and universities. He contributes to the technology transfer by the joint project as a leading expert of Hydroponics.

\section{Recent publications}

1. Tsukagoshi S, Takano A, Hohjo M, et al. Evaluation of some local cultivars of carrot in terms of the suitability as materials for "Yakuzen" dishes. J Trad Med. 2011;28:106-114.

2. Tsukagoshi S, Kuroda K, Hohjo M, et al. Evaluation of local eggplant cultivars in terms of suitability as materials for "Yakuzen" dishes. Adv Hort Sci. 2014;28:102-110.

3. Tsukagoshi S, Shinohara Y. Plant Factory: An Indoor Vertical Farming System for Efficient Quality Food Production. Academic Press. 2015;11:165-172

4. Tsukagoshi S, Hamano E, Hohjo MF, et al. Hydroponic production of low-potassium tomato fruit for dialysis patients. Int J Veg Sci . 2016;22: 451-460.

5. Maneejantraa N, Tsukagoshi S, Lu N, et al. A quantitative analysis of nutrient requirements for hydroponic spinach (Spinacia oleracea L.) production under artificial light in plant factory. 2016.

\section{References}

1. Cindy Mayorga, Satoru Tsukagoshi, Anna Sasaki, et al. Effect on the Growth and Nutritional Components in Two Red Lettuces (Lactuca Sativa L.) Cultivated Under UV Light in a Mini Plant Factory. 2019.

2. FB Abeles, PW Morgan, ME Saltveit, et al. Ethylene in Plant Biology. Academic Press. 1992;83-119.

3. GH Bates. Life forms of pasture plants in relation to treading. J Ecol. 1938;26:452-454.

4. CWPM Blom. Separate and combined effects of trampling and soil compaction on the growth of four Plantago species on experimental plots. Progress Report. 1978;71:299-303.

5. N Boyer, MO Desbiez, M Hofinger, et al. Effect of lithium on thigmomorphogenesis in Bryonia dioica. Ethylene production and sensitivity. Plant Physiol. 1983;72:522-525.

6. RF Burden, PF Randerson . Quantitative studies of the effects of human trampling on vegetation as an aid to the management of semi-natural areas. J Appl Ecol. 19729:439458.

7. WMHG Engelaar, CWPM Blom. Effects of flooding and trampling on the performance of river foreland species of Rumex and Plantago. Acta Bot Neerl 1995;44:225-245.

\author{
*Correspondence To: \\ Satoru Tsukagoshi \\ University of Chiba \\ Japan \\ E-Mail: tsukag@faculty.chiba-u.jp
}

